\title{
In memoriam: Jonathan S. Allan, DVM (1952-2009)
}

\author{
Louisa E. Chapman
}

Published online: 12 December 2009

(C) Springer-Verlag 2009

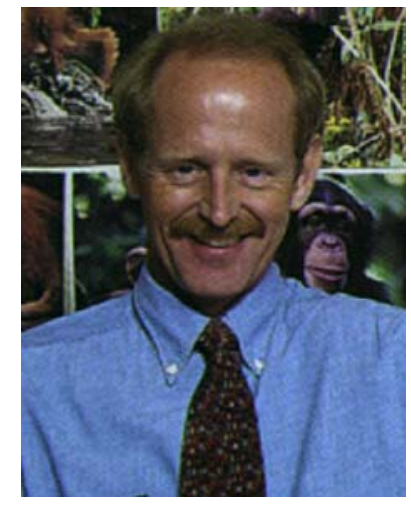

Jonathan S. Allan, DVM, a 57-year-old internationally respected bioscientist and former mayor of Helotes, Texas, died peacefully at home on 28 September 2009. Jon was diagnosed with a stage 4 glioblastoma, a brain cancer, about 14 months earlier. Jon is survived by two brothers, his mother in New Hampshire, his beloved dog Millie, the wild hogs surrounding his Texas hill country cabin, and a wide community of friends who often met Jon through his science but remained connected primarily because of his humanity.

A native of Boston, Jon earned a Bachelor's degree at Purdue University in W. Lafayette, Indiana, a Master's degree in Microbiology at Vanderbilt School of Medicine in Nashville, Tennessee, and a degree in Veterinary Medicine from Michigan State University in East Lansing,

L. E. Chapman $(\square)$

National center for Zoonotic, Vector-borne and Enteric Diseases, Centers for Disease Control and Prevention, Mailstop D 75, 1600 Clifton Road, Atlanta, GA 30333, USA

e-mail: lec3@cdc.gov
Michigan. He returned to Boston in the mid-1980s to complete post-doctoral work in Virology at Harvard University School of Public Health.

Jon came of age as a microbiologist in parallel with the emergence of AIDS, a zoonotic retrovirus infection. Many of his publications in the 1980s explore aspects of "human T-lymphotropic virus III", later renamed as human immunodeficiency virus. He was best known in scientific circles for his contributions to seminal studies that characterize HIV as the causative agent of AIDS. He was an early pioneer in research with nonhuman primates exploring why simian immunodeficiency virus (SIV)-infected African monkeys remain asymptomatic while SIV-infected Asian monkeys develop AIDS, and recently coauthored a review on this issue in the August 2009 issue of Nature Medicine (Towards an AIDS vaccine: lessons from natural simian immunodeficiency virus infections of African nonhuman primate hosts. Nat Med 15:861-865, 2009).

Jon was foremost a veterinarian and public health bioscientist with a special interest in the transmission of zoonotic agents between species. Jon's imagination was captured by the ecology of infection and disease, in particular by exploration of the characteristics of the host and virus that contribute to differential patterns of disease when retroviruses transmit between species. His interests led him in 1987 to join the Southwest Foundation for Biomedical Research as an Assistant Scientist in the Department of Virology and Immunology where he was promoted to Scientist in 1992, was involved in preparing the initial base grant application that led to the establishment of the Southwest National Primate Research Center (SNPRC) in 1999, and served as Leader of the SNPRC Retrovirus Diagnostics Laboratory until his death. In this position, Jon played a critical role in screening the baboon colony for 
retroviruses and continued studies of patterns of retroviral disease. His welcoming personality and scientific expertise made Jon particularly adept at collaborating with scientists from divergent fields ranging from transplantation immunology to biological anthropology and public health. Jon pursued his interest in understanding alterations in virulence patterns when retroviruses moved between species through the study of nonhuman primate models used to elucidate human diseases including AIDS and cancer. Jon did seminal work on foamy viruses, including work on simian foamy virus (SFV) in free-ranging primates and in humans in Asia. He was one of the first virologists who appreciated the real-world implications of retroviral transmission in areas where humans and monkeys share an ecologic niche. In latter years, his work focused on the pathogenesis of SIV and the factors controlling infection and progression of simian retroviral disease.

Jon was among the first to recognize the implications of his studies of HIV and interspecies infections in the emerging field of xenotransplantation. He was a major voice in advocating careful studies and monitoring of emerging biotechnologies, which brought viable tissues from different species together. In particular, he recognized the risks inherent in technologies aimed at the use of biological material from other species in humans to cure or ameliorate disease. Jon reasoned that microbiologically unscreened xenogeneic biomaterials, in particular carrying latent viral infections, could be inadvertently transferred with risk to both the recipient and to the larger community. Jon's reasoned discourse concerning these issues resulted in his engagement in a body of work that began during the 1990s and led to the development of the public health science and policy that underlies global regulatory policy for xenotransplantation and related biotechnologies today. In 1995, a controversial experiment attempted to cure AIDS by transplanting baboon bone marrow into an HIVpositive individual. Jon perceived a risk that this experiment might unintentionally introduce additional simian retroviruses into the human community, and was the only member of an early Advisory Committee convened by the US Food and Drug Administration (FDA) who voted against recommending to the FDA that the protocol be allowed to go forward-in the face of strong public and private opposition to his stance. When the experiment did proceed, Jon constructively engaged with the scientific community working to develop xenotransplantation science as both a scientist and a public advocate in ways that were thoughtful, principled and effective. He later served on the Department of Health and Human Services Secretary's Advisory Committee on Xenotransplantation (SACX). He also voiced his concerns regarding simian retrovirus transmission to humans as a consultant to the
2001 FDA Blood Product Advisory Committee (BPAC) in the context of blood donors infected with SFV. Jon was always generous in response to requests for public service. He served a total of 14 years as a member of or consultant to various FDA Advisory Committees in addition to his service with the SACX.

Jon was an excellent, careful and thoughtful scientist. In this role, he contributed much to the understanding, clarification and description of virology science relevant to xenotransplantation. What distinguished Jon were his clear scientific reasoning, his generosity of spirit, and his ability to see retrovirology in a larger context. Jon consistently recognized and communicated the larger implications of novel science. He had the courage and willingness to serve as a public spokesperson for those views, even when they were unpopular. His principles often led to conflict within his own organizations, in public forums, and also with the HIV-AIDS community to which he had dedicated his early career. Jon's greatest legacy was his insistence that science at the bench be framed in the larger societal context and his ability to articulate those views in a clear and compelling manner for the benefit of many others-even when it would have been far more convenient and safer professionally for him to have remained silent.

Jean Patterson, chairwoman of the department of virology and immunology at the Southwest Foundation, said that "Jon looked at science in a global way. He didn't just think about his science, but about how all science worked together in the global community."

As a scientist and as a human being, Jon Allan focused on the greater good, and lived the values that many profess but rarely follow into controversy. Jon's scientific expertise was seamlessly connected to his forthrightness and passionate concerns for public health. Jon's propensity to advocate for the greater good carried over from his scientific to his personal life, leading him to serve one term as mayor of Helotes, Texas and to found both the Helotes Heritage Association and a Buddhist mediation center, Yellow Dog Sangha. His love of the Texas hill country shone through his eyes when he spoke about it and ignited passion in others. Those who were privileged to know Jon beyond the public sphere remember his generosity as a friend, his wry sense of humor, his great love for his Texas hill country land and the wild hogs that cohabitated on it, and for his dogs Millie and Jack. Jon was a compassionate person, an insightful scientist, and a great observer of both the big picture and the important details where most of life is lived. In his integrity as a scientist and a human being, through both his values and his fidelity in living those values, in his confidence that science should enhance lives fully lived beyond the laboratory, Jon continues to instruct us. We will miss him greatly. 
Submitted respectfully on behalf of the world's community of virology, of xenotransplantation, and of emerging infections.

Louisa E Chapman MD, Public Health Epidemiologist and Infectious Disease Physician

Julia Hilliard PhD, Herpes Virologist/Immunologist

Lisa Jones-Engel PhD, Biological Anthropologist

Arifa S. Khan PhD, Retrovirologist
Harold Vanderpool PhD, Professor of History and Philosophy of Medicine

Daniel Salomon MD, Nephrologist and Transplant Physician

Megan Sykes MD, Transplant Immunologist

Jay Fishman MD, Infectious Disease and Transplant Physician 